\title{
East African ROAD
}

\section{Kelali Tekle}

East African Regional Office of Astronomy for Development, Addis Ababa, Ethiopia

\begin{abstract}
In the developing world astronomy had been treated as the science of elites. As a result of this overwhelming perception, astronomy compared with other applied sciences has got less attention and its role in development has been insignificant. However, the IAU General Assembly decision in 2009 opened new opportunity for countries and professionals to deeply look into Astronomy and its role in development. Then, the subsequent establishment of regional offices in the developing world is helping countries to integrate astronomy with other earth and space based sciences so as to progressively promote its scientific and development importance. Gradually nations have come to know that space is the frontier of tomorrow and the urgency of preeminence on space frontier starts at primary school and ascends to tertiary education. For this to happen, member nations in east African region have placed STEM education at the center of their education system. For instance, Ethiopian has changed University enrollment strategy to be in favor of science and engineering subjects, i.e. every year seventy percent of new University entrants join science and engineering fields while thirty percent social science and humanities. Such bold actions truly promote astronomy to be conceived as gateway to science and technology. To promote the concept of astronomy for development the East African regional office has actually aligned it activities to be in line with the focus areas identified by the IAU strategy (2010 to 2020).
\end{abstract}

\section{Universities and Research}

In the triple helix approach Universities are epicenter of qualified workforce production. Universities incorporate what we call the three pillars of successful learning: education, perspective and inspiration. Education includes understanding how science uses observation and logical thinking to learn about the world around us; perspective shows students how what they are learning can affect their views on their own lives and on humanity's place in the universe; and inspiration encourages students' want to learn more, and to think about how they personally can help make their world a better place for human kind. Such knowledge transaction places Universities to be sources of wisdom in Research and Development. For the sake of expanding the knowledge horizon in astronomy, the regional office is closely working with Universities and research institutions. Up until recently it was difficult to offer astronomy and space science courses in universities. Now the situation is progressing very fast: many public Universities have started offering $\mathrm{PhD}$ and MSc Programs in astronomy and space science and technology which is a big step towards furtherance of astronomy for development. Entoto Observatory and Research Center (EORC) which is serving as the research center of the regional office is teaching 18 students in $\mathrm{PhD}$ and 8 students in MSc. In close consultation with EORC, the regional office has secured two scholarships for East African students in Astronomy.

\section{School and Children}

The regional office believes that the easiest way to explore global knowledge in astronomy at ease is to open access to education for boys and girls through robust STEM curricula. Since we put more emphasis on STEM subjects, the number of schools involved 
in space science clubs increased at a faster rate; more and more students are participating in astronomy program activities, parents and teachers are continuously expressing their interest to support space science programs. This is one of the promising activities of the regional office in advancing the science of astronomy for development because future school of astronomy will entirely depend on member countries performance in STEM education at all levels. In all the awareness programs, conference and workshops organized and hosted by the ROAD, students, teachers, academicians, researchers and volunteers have participated, and the office is committed to broaden this experience in member countries.

\section{Public Outreach}

For the last one year, the regional office has spent much of its time in promoting public awareness towards astronomy for development. Member countries' policy decisionmakers, academic and research institutions, private sector and the general public have been the focus in its awareness promoting programs. Specifically:

(a) the regional office and EORC jointly organized and hosted East African Astronomical Society and ROAD granted US\$ 5000 for the conference to be successful;

(b) the regional office was invited to participated in the 3rd international conference on "Financing for Development" held in Addis Ababa, Ethiopia and to present a paper under the sub-theme African-European Radio Astronomy platform. ROAD was among the 14 sectors selected by the national exhibition committee to exhibit its program activities along with Ethiopia Space Science Society. The president of the Federal Democratic Republic of Ethiopia who was the guest of honor expressed his hearth felt appreciations and pledged to help the space program to achieve its set out objectives;

(c) The oversight committee decided to approach member countries to own and commit resources for the regional office to play its role in promoting astronomy for development in particular and the space science and technology in general. Accordingly a delegation led by the former deputy prime ministry of Ethiopia and board chair of Entoto observatory and research center visited Uganda, Rwanda and Tanzania. The delegation met with respective ministers in charge of space science and technology in each member state and has agreed to promote space science and technology to be a driving force for sustainable development. The unwavering commitment of member states to advance importance of space science and technology encouraged the delegation to visit the other member states. The visit to other member countries will be made before the end of this year. Onces the visit is over there will be a regional conference to be hosted here tentatively end of January 2016.

(d) The regional office made experience sharing visit to Republic of Korea, USA and has scheduled to visit India this coming November.

The office, under the guidance of the oversight committee, is working to broaden the mandate of reaching member countries to promote astronomy for development in a pragmatic way. 